\title{
ETHANOLIC EXTRACTS OF HEDYOTIS CORYMBOSA L. IMPROVES MONOSODIUM IODOACETATE-INDUCE OSTEOARTHRITIS IN RAT
}

\author{
ANTON BAHTIAR ${ }^{1}$, FITRI ARUM SARI ${ }^{1}$, MEGA AUDINA ${ }^{1}$, NATASHA LINSIE CORONA DATUNSOLANG ${ }^{1}$, \\ ADE ARSIANTI ${ }^{2}$
}

${ }^{1}$ Department of Pharmacology and Toxicology, Faculty of Pharmacy, Universitas Indonesia, Kampus UI Depok 16424, Indonesia. ${ }^{2}$ Department of Medicinal Chemistry, Faculty of Medicine, Universitas Indonesia, Kampus UI Salemba, Indonesia. Email: anton.bahtiar@gmail.com

Received: 12 December 2016, Revised and Accepted: 24 December 2016

ABSTRACT

Objective: The objective of this study is to explore the effects of the $70 \%$ ethanolic extract of pearl grass on the immune system of the osteoarthritis model rat, characterized by the number of leukocytes and lymphocytes, and the histology of the joint. Osteoarthritis is a degenerative disease characterized by chronic inflammation in the joints. Based on the daily practice of herbal medicine in some community in Indonesia, pearl grass usually used for anti-inflammation but not a lot of data to support it.

Methods: We used 36 male rats Sprague-Dawley strain divided into 6 groups. Normal group was given $0.5 \%$ of CMC, the negative control group was given $0.025 \mathrm{ml}$ of sodium iodoacetate in $0.9 \%$ saline, the positive groups control group was given a suspension of glucosamine-chondroitin $135 \mathrm{mg} / 200 \mathrm{~g} b \mathrm{~b}$, three were given pearls grass extract in various dose $5.625 \mathrm{mg}, 11.25 \mathrm{mg}$, and $22.5 \mathrm{mg}$, respectively. 28 days after sodium iodoacetate induction, the extracts were given orally once daily for 21 days. Measurement of inflammation of knee joint and the number of leukocytes and lymphocytes were counted on day $14^{\text {th }}, 28^{\text {th }}$, and $49^{\text {th }}$ after sodium iodoacetate induction. After treatment, all rats were sacrified and all knee joints were collected to subject for histology.

Results: The results showed that the extract of pearl grass in all doses was able to decrease the number of leukocytes and lymphocytes significantly and prevent proteoglycan degradation. The results showed that the extract of pearl grass with a given dose variations have antiinflammation effect and been able to protect proteoglycan significantly.

Conclusion: Doses 3 (22.5 mg/200 g BW) is the best result. These results indicate that pearl grass can be further investigated as a treatment for osteoarthritis.

Keyword: Osteoarthritis, Sodium iodoacetate, Pearl grass, Hedyotis corymbosa L. Lamk., Immune system.

(c) 2017 The Authors. Published by Innovare Academic Sciences Pvt Ltd. This is an open access article under the CC BY license (http://creativecommons. org/licenses/by/4. 0/) DOI: http://dx.doi.org/10.22159/ajpcr.2017.v10i3.16558

\section{INTRODUCTION}

Osteoarthritis is a chronic disease involving the long-term depletion of cartilage in the joints that causes bone friction resulting in stiffness, pain, and effect of movement of the body [1]. Osteoarthritis is common in the elderly, the prevalence of osteoarthritis vary in each country, but data on many countries show that the most common type of arthritis is osteoarthritis [2]. According to the World Health Organization in 2004, osteoarthritis affects 151.4 million persons worldwide and reach 27.4 million people in Southeast Asia. In general, the prevalence of joint disease in Indonesia is very high at $30.3 \%$. At the age of 65-74 year old have $62.9 \%$ and over 75 years old amounted to $65.4 \%$. The prevalence of osteoarthritis total in Indonesia to 34.3 million people in 2002 and reach 36.5 million people in 2007.

The main purpose of osteoarthritis treatment is to improve the quality of life in a way relieve pain, reduce inflammation, slow cartilage degradation, improve joint function, and reduce disability. Pain and inflammation can occur due to the depletion layer of articular cartilage and then bone friction. Cartilage is composed of water, chondrocytes cells, collagen, and proteoglycans. In the condition of osteoarthritis, proteoglycans decline due degeneration of cartilage. Proteoglycans decrease was due to the inflammatory response of the destructive extracellular matrix enzymes that inhibits the synthesis of proteoglycans $[2,3]$.

The treatment of osteoarthritis can be grouped into three major groups, namely, non-pharmacologic therapy; pharmacologic therapy (analgesics, non-steroid anti-inflammatory drugs, supplements (glucosamine and chondroitin sulfate), intraarticular steroid injection, various rubefacients, symptomatic slow-acting drugs in); and surgery [4]. Glucosamine and chondroitin sulfate is effective in the treatment of osteoarthritis. Glucosamine works as stimulator of the synthesis of proteoglycans and chondroitin sulfate is involved in the formation of cartilage matrix degenerate back. However, glucosamine and chondroitin sulfate cannot be consumed by osteoarthritis patients who have a history of allergy to marine animals [5-7]. In addition, glucosamine and chondroitin sulfate can cause side effects on gastrointestinal, diarrhea, nausea, and pyrosis [8].

Recently, the use of herbal medicines were increasingly in demand by the public, several herbal medicine are used in various forms for the treatment of osteoarthritis in the whole world. Pearl grass (Hedyotis corymbosa (L.) Lamk) is one of the plants that contain natural antiinflammatory. This plant contains flavonoids which have been reported as an antioxidant and can also give rise to anti-inflammatory effects [9]. In addition, pearl grass can also be used for the treatment of liver cancer and able to reduce the proliferation of breast cancer cells.

In this study, we found that $H$. corymbosa (L.) Lamk could improve inflammation after treatment by monosodium iodoacetate by suppresing an immune system and repair cartilage by inducing proteoglycan.

\section{METHODS}

Plant and chemical materials

Simplicia Pearl grass (H. corymbosa L. (Lamk)) was extracted by maceration using $70 \%$ ethanol for $3 \times 24$ hrs then concentrated by rotary evaporator at a temperature of $40-50^{\circ} \mathrm{C}$. 
Chemicals material which is used in this experiment is sodium iodoacetate (Sigma), glucosamine (PT Nutrend), 10\% Neutral buffer formalin, sterile $0.9 \%$ sodium chloride, CMC (BRATACO Chemical), $70 \%$ ethanol, ether, propofol, and distilled water

\section{Animals}

36 female rats was randomized to 6 groups and induced by monosodium iodoacetate. Rats induced by intraarticular injection of sodium iodoacetate in the knee of rat that had been anesthetized using ketamine $24 \mathrm{mg} / 200$ grams of rats by intramuscular injection. Observation of edema using plethysmometer was done on day 0 before induction, day $7^{\text {th }}, 14^{\text {th }}, 21^{\text {th }}, 28^{\text {th }}, 36^{\text {th }}, 43^{\text {th }}$, and $50^{\text {th }}$ after the induction of sodium iodoacetate; then, day 28 and 50 were observed for hematology assay. After treatment is completed, all rats were sacrificed using ether to take knee joint of the left leg. Osteoarthritis activity seen through changes in the amount of proteoglycans that are characterized by staining safranin 0 -fast green [10].

\section{Calculation of total leukocytes and lymphocytes}

Hematology parameters were evaluated by counting the number of leukocytes and lymphocytes using medonic hematology analyzer. Counting the number of blood cells is done by taking a blood sample from a vein in orbital sinus [11]. Tests were conducted in tubes containing blood samples K3 ethylenediaminetetraacetic acid (EDTA) to avoid precipitation of blood [11]. Calculation of the hematology analyzer using dilution method. This tool is principled on spectrophotometer methods, the number of cells to determine the value of leukocytes calculated from the ratio of the amount of whole blood dilution measured.

\section{Spleen weight determination}

Spleen weight determination was performed on the last day of the experiment. The rats were sacrificed by anesthetized using ether and then dissected in the abdomen and spleen were taken and weighed.

\section{Histology}

Knee joints were placed in $10 \%$ buffered formalin for 24 hrs followed by decalcification in 20\% EDTA. The progression of the decalcification was assessed by X-ray and required approximately 14-21 days. The fixed, decalcified tissue was embedded in paraffin and was processed using conventional dehydrating and clearing agents and cut by microtom; then, the sections were stained by safranin 0-fast green [12]

\section{RESULTS AND DISCUSSION}

This study was conducted to analyze the anti-osteoarthritis effects of the $70 \%$ ethanolic extract of pearl grass (H. corymbosa (L.) Lamk). To this end, 36 six male rats were made osteoarthritis by sodium iodoacetate induction method. The anti-inflammatory evaluation done by measuring the volume of rat knee edema using plethysmometer and evaluated proteoglycan changes by histologic examination of the cartilage rat knee.

Pearl grass plants which have been used empirically as antiinflammatory in some part of Indonesian Villages. The material was administered as a $70 \%$ ethanol extract. The doses for this experiment were used three doses levels, namely, $5.625 \mathrm{mg}, 11.25 \mathrm{mg}$, and $22.5 \mathrm{mg} / 200 \mathrm{~g}$ BW rats. This was based on the calculation of pearl grass amount in empirical studies. The solvent that used for the extraction of pearl grass is $70 \%$ of ethanolin order toget flavonoids as the polar active compounds. In addition, ethanol is evaporated and distillated easily so can save time [13].

Based on the calculations, maceration of $1600 \mathrm{~g}$ of dry powder pearl grass produced $50 \mathrm{~g}$ extract, so the yield was $3.125 \%$.

\section{Anti-inflammatory effects}

We divided 36 rats to 6 groups, namely, normal control, negative control, positive control, and three level doses of pearl grass as mention above. On the day 1 , the rats were induced by intra-articular of sodium iodoacetate at the left knee joint as much as $0.25 \mathrm{mg}$. Induction of sodium iodoacetate will be degradated cartilage of chondrocytes [14]. Inflammation can occur as a result of the degradation of cartilage until the cartilage rub together. The effects of monosodium iodoacetate can be seen at the Fig. 1 after 28 days treatment. Volume measurement of edema caused by inflammation performed using a plethysmometer [15].

We then treated monosodium iodoacetate-treated rat by the extract of Pearl grass for 21 days, after 28 days induction, and edema measurements performed on day 0 before induction, day $7^{\text {th }}, 14^{\text {th }}$, $21^{\text {th }}, 28^{\text {th }}, 36^{\text {th }}, 43^{\text {th }}$, and $50^{\text {th }}$. The positive control was used in this experiment is a combination of glucosamine and chondroitin sulfate. We choose of glucosamine to stimulate proteoglycan synthesis and inhibiting the degradation of proteoglycans, as well as stimulate cartilage regeneration after damage [16]. While chondroitin sulfate has a role in creating osmotic pressure sufficient to expand the matrix and collagen network [17]. Average edema volume of each group at day $7^{\text {th }}$, $14^{\text {th }}, 21^{\text {th }}, 28^{\text {th }}, 36^{\text {th }}, 43^{\text {th }}$, and $50^{\text {th }}$ can be seen in Fig. 2 . Fig. 2 showed that an increase in the volume of edema in all groups except normal control on day 0 to day 28. On the negative control group was increased edema volume at day 36 but on days 43 and 50 a decline in the volume of edema, which is $3.7,4.08,4.43,4.55,4.93,5.5,5.25$, and $4.8 \mu \mathrm{L}$. On the dose 1 group showed the decreased of average volume of edema at day 36 , then, there is no change in the average volume of edema at day 43 and dropped back on the $50^{\text {th }}$. Meanwhile, the dose 2 group showed the average of edema volume was decreased on day 36 , then there is no change in the average volume of edema at day 43 , then rose again on day 50. Dose 3 group showed an average of reduction of edema volume

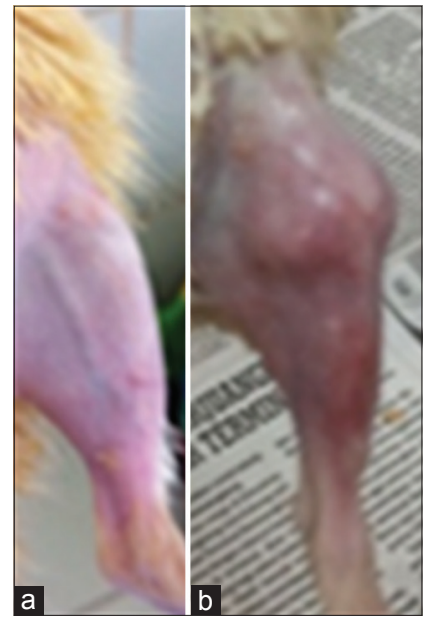

Fig. 1: The effects of monosodium iodoacetate on knee joint of the rat. (a) untreated rat, (b) treated rat

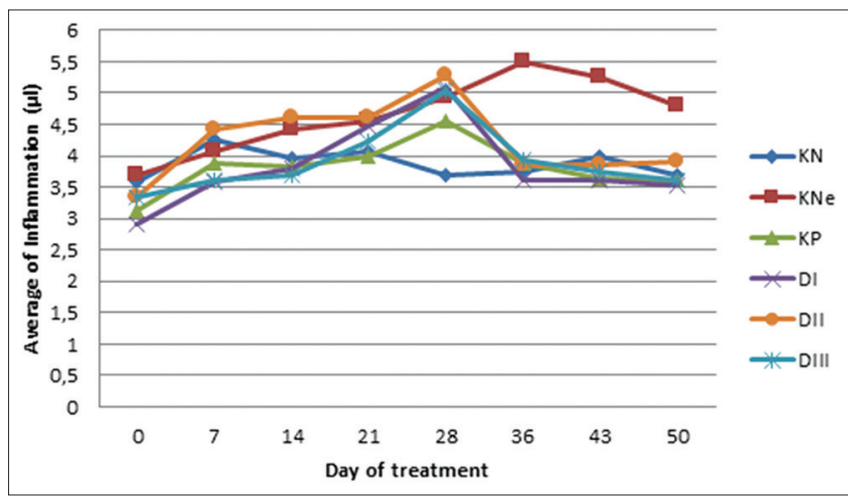

Fig. 2: Inflammation profile during experiment. KN: Normal control, KNe: Negative control, KP: Positive control, D2: Dose 1, D2: Dose 2, D3: Dose 3 
every week. A decrease in the average volume of edema at day 36 to day 50 was also found in the positive control group. Fig. 2 also shown that the pearl grass extract can reduce the symptoms of arthritis.

The effects of $\boldsymbol{H}$. corymbosa extracts on the number of leukocyte and lymphocyte cells

Tables 1 and 2 showed that the groups that were treated by monosodium iodoacetate (negative control, positive control, and doses 1-3) for 28 days, the number of leukocytes and lymphocytes were increased significantly compared with normal group which did not treat by monosodium iodoacetate. This indicates successfully of induction with monosodium iodoacetate which causes inflammation and an increase in immune system parameters. This is confirmed the finding that osteoarthritis increased T lymphocytes as a non-specific immune parameters. After day $50^{\text {th }}$, in negative control groups, the number of leukocytes and lymphocytes became more higher $17.25 \pm 3.15 \times 10^{9} / \mathrm{L}$ and $15.05 \pm 1.35 \times 10^{9} / \mathrm{L}$, respectively. After 21 days, treatment by pearl grass extracts, the numbers of leukocytes and lymphocytes decreased significantly compare with negative groups. This decreasing effects of pearl grass-treated group was relates to the active substances therein are flavonoids that are known to have the effect of chronic inflammation.

Table 1: The effects of Hedyotis corymbosa extracts on the number of leukocyte

\begin{tabular}{lll}
\hline Groups & \multicolumn{2}{l}{$\begin{array}{l}\text { The number of leukocyte }(\times \mathbf{1 0} \\
\text { deviation }\end{array}$} \\
\cline { 2 - 3 } & Before & After \\
\hline Normal & $9.58 \pm 1.89$ & $10.57 \pm 1.55$ \\
Negative control & $16.75 \pm 4.60^{*}$ & $17.25 \pm 3.15^{*}$ \\
Positive control & $15.78 \pm 2.53^{*}$ & $13.3 \pm 3.41^{\#}$ \\
Dose 1 & $16.7 \pm 5.21^{*}$ & $15.27 \pm 3.05^{\#}$ \\
Dose 2 & $15.46 \pm 3.15^{*}$ & $13.07 \pm 1.88^{\#}$ \\
Dose 3 & $18.67 \pm 3.77^{*}$ & $11.92 \pm 2.02^{\#}$ \\
\hline
\end{tabular}

*Significantly different with normal groups ( $\mathrm{p}<0.05)$, "significantly different with negative control groups $(\mathrm{p}<0.05)$, Before column $=28$ days of monosodium iodoacetate treatment, After column=21 days treatment by pearl grass/ glucosamine-chondroitin

Table 2: The effects of Hedyotis corymbosa extracts on the number of lymphocyte

\begin{tabular}{lll}
\hline Groups & \multicolumn{2}{l}{$\begin{array}{l}\text { The number of } \\
\text { lymphocyte }(\mathbf{\times 1 0} \mathbf{1 0}) \pm \text { standard deviation }\end{array}$} \\
\cline { 2 - 3 } & Before & After \\
\hline Normal & $5.65 \pm 1.13$ & $6.22 \pm 1.93$ \\
Negative control & $9.26 \pm 1.37^{*}$ & $15.05 \pm 1.35^{*}$ \\
Positive control & $7.73 \pm 2.66^{*}$ & $7.5 \pm 2.14^{\#}$ \\
Dose 1 & $10.16 \pm 1.75^{*}$ & $8.6 \pm 1.83^{\#}$ \\
Dose 2 & $10.13 \pm 2.64^{*}$ & $7.9 \pm 1.30^{\#}$ \\
Dose 3 & $13.06 \pm 3.91^{*}$ & $8.14 \pm 2.14^{\#}$ \\
\hline
\end{tabular}

*Significantly different with normal groups ( $<<0.05)$, " significantly different with negative control groups $(\mathrm{p}<0.05)$, Before column=28 days of monosodium iodoacetate treatment, After column=21 days treatment by pearl grass / glucosamine-chondroitin

Table 3: The effects of pearls grass on spleen protection

\begin{tabular}{ll}
\hline Groups & Average of spleen weight \pm standard deviation \\
\hline Normal & $0.43 \pm 0.13$ \\
Negative control & $0.62 \pm 0.19^{*}$ \\
Positive control & $0.386 \pm 0.14^{\#}$ \\
Dose 1 & $0.61 \pm 0.23$ \\
Dose 2 & $0.43 \pm 0.09^{\#}$ \\
Dose 3 & $0.44 \pm 0.08^{\#}$ \\
\hline
\end{tabular}

*Significantly different with normal groups ( $\mathrm{p}<0.05)$, "Significantly different with negative control groups $(\mathrm{p}<0.05)$
Flavonoids work as anti-inflammatory mechanism is through inhibition of the release of proinflammatory cytokines that trigger activation of the immune system [18]. Other studies also show that the flavonoid compound of pearls grass have nonspecific immune effects by suppressing the activation of macrophages and lymphocytes. We also found that the quercetin that contain in the pearl grass have $1.52 \%$ in the extract. Therefore, it can be concluded that the $70 \%$ ethanol extract pearls have potential as anti-inflammatory and immunomodulator.

\section{Spleen weight analysis}

The spleen is an organ that is associated with the immune system. The spleen produces lymphocytes and white blood cells maturation and sent it through the body through the lymph nodes. We have evaluated the spleen of osteoarthritis model rat as shown in Table 3. The positive group has lowest weight of spleen and negative group is the group with the highest spleen weight compared to other groups. Treatment with pearl grass showed that doses 2 and 3 could decrease the enlargement of spleen.

In other arthritis, other researcher found an enlarged spleen in patients with RA might be caused by a mechanism similar to that in Felty's syndrome, in which white blood cells are sequestered in the spleen to clear the circulating immune complexes. Hence, we though in osteoarthritis also occurred splenomegaly. Rat with splenomegaly correlated with infection or osteoarthritis, triggering spleen to continued to produce white blood cells as asystemic immune response. In rat osteoarthritis model, the average weight of the spleen is larger than normal mice. From these data, it seems that sodium iodoacetateinduced splenomegaly. In conclusion, severe osteoarthritis affects the spleen because of the close relation with the proliferation of lymphocytes in the event of infection.

The effects of $\boldsymbol{H}$. corymbosa extracts on histology of knee joints Histological observations of the left knee joint were evaluated day $50^{\text {th }}$. Observations on the $50^{\text {th }}$ day of treatment carried out after the ratinduced sodium iodoacetate were sacrificed. To evaluate histological data, we used proteoglycans specific dye that is $1 \%$ safranin 0 for 5 minutes and $0.02 \%$ fast green for 5 minutes after staining orientation.
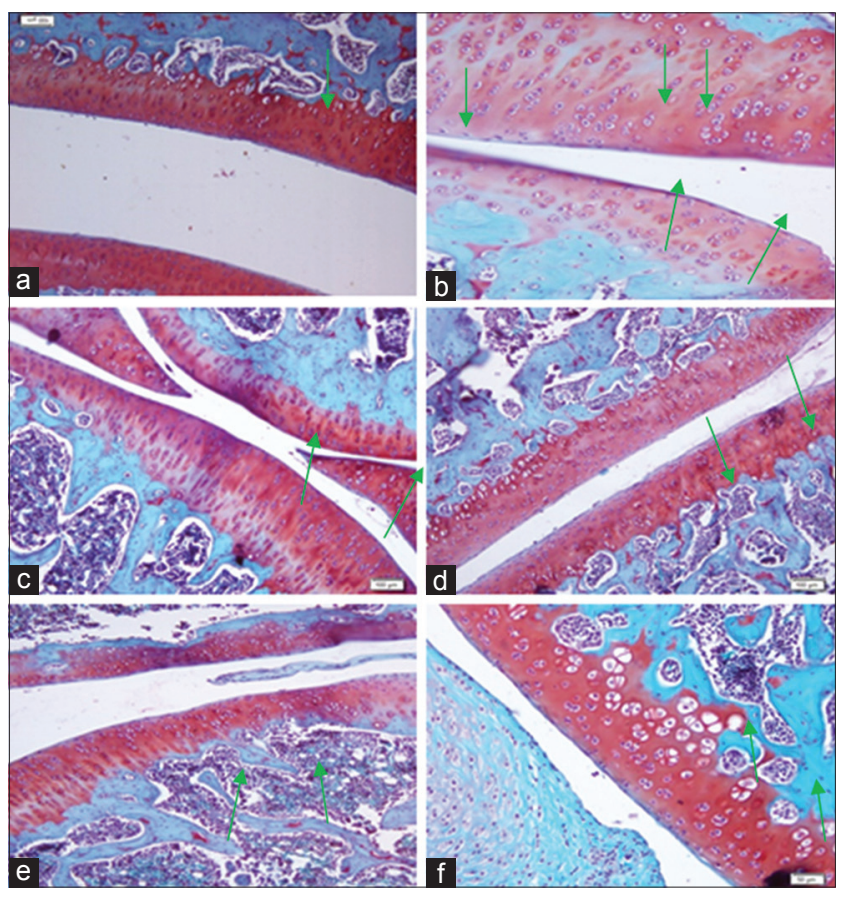

Fig. 3: The histology of knee joint in osteoarthritis model rat after Pearl grass extract treatment. (a) Normal control, (b) Negative control, (c) Positive control, (d) Dose 1, (e) Dose 2, (f) Dose 3, green arrow: Proteoglycan staining 
The knee joint was performed decalcification, fixation, cutting, parafinization, mounting, and staining. The specimens were observed using of light microscopy and the color intensity was calculated by Image J software.

According to Fig. 3, the intensity of the color of the positive control has a color intensity above normal controls while negative controls had normal color intensity under control. This indicated that osteoarthritis model rat has decreased proteoglycan content compared with normal group. In the treated group, a dose $3^{\text {rd }}$ has the highest color intensity than the normal controls, a positive control, negative control, dose $1^{\text {st }}$ and $2^{\text {nd }}$. These results indicated that pearl grass extract could recover the loss of proteoglycan in osteoarthritis rat.

Finally, we evaluated total flavonoid concentration as quercetin for pearl grass extract by Spectrophotometer and found that $1.52 \%$. Hence, it contains $8.55 \mu \mathrm{g}-34.2 \mu \mathrm{g}$ for dose 1-3. The actual mechanism still in progress whether the flavonoid really block the tumor necrosis factor-a or MMP-1/3 to reduced inflammation and protect proteoglycan is still in progress.

\section{REFERENCES}

1. Haq I, Murphy E, Dacre J. Osteoarthritis. Postgrad Med J 2003;79(933):377-83.

2. Lad H, Dixit D, Joshi A, Bhatnagar D. Antioxidant and antiinflammatory effects of vitex negundo on freund's complete adjuvant induced arthritis. Int J Pharm Sci 2015;7(1):81-5.

3. Paul S, Das A, Bhattacharjee S. Rheumatoid arthritis: Molecular basis and cures from nature. Int J Pharm Sci 2015;7(7):30-9.

4. Hochberg MC, Dougados M. Pharmacological therapy of osteoarthritis. Best Pract Res Clin Rheumatol 2001:15(4):583-93.

5. Matheu V, Gracia Bara MT, Pelta R, Vivas E, Rubio M. Immediatehypersensitivity reaction to glucosamine sulfate. Allergy 1999;54(6):643.

6. Tallia AF, Cardone DA. Asthma exacerbation associated with glucosamine-chondroitin supplement. J Am Board Fam Pract 2002;15(6):481-4.

7. Danao-Camara T. Potential side effects of treatment with glucosamine and chondroitin. Arthritis Rheum 2000;43(12):2853.

8. Huskisson EC. Glucosamine and chondroitin for osteoarthritis. J Int Med Res 2008;36(6):1161-79.

9. Lu CM, Yang JJ, Wang PY, Lin CC. A new acylated flavonol glycoside and antioxidant effects of Hedyotis diffusa. Planta Med 2000;66(4):374-7.

10. Janusz MJ, Hookfin EB, Heitmeyer SA, Woessner JF, Freemont AJ, Hoyland JA, Brown KK, Hsieh LC, Almstead NG, De B, Natchus MG, Pikul S, Taiwo YO. Moderation of iodoacetate-induced experimental osteoarthritis in rats by matrix metalloproteinase inhibitors. Osteoarthritis Cartilage 2001;9(8):751-60.

11. Hoff J. Method of blood collection in the mouse. J Lab Anim 2000;29(10):47-53.

12. Pritzker MD, Gay MD, Jimenez SA. Osteoartritis cartilage histopathology: Grading and staging. J Osteoartritis Res Soc Int 2006;14(1)721-32.

13. Sathishkumar T, Baskar R, Shanmugam S, Rajasekaran P, Sadasivan S, Manikandan V. Optimization of flavonoids extraction from the leaves of Tabernaemontana heyneana Wall using L16 orthogonal design. Nat Sci 2008;6(3):10-21.

14. Bove SE, Calcaterra SL, Brooker RM, Huber CM, Guzman RE, Juneau PL, et al. Weight bearing as a measure of disease progression and efficacy of anti-inflammatory compounds in a model of monosodium iodoacetate-induced osteoarthritis. Osteoarthritis Cartilage 2003;11(11):821-30.

15. Woode E. Anti-arthritic and antioxidant properties of the ethanolic stem bark extract of Newbouldia laevis (P. Beauv.) Seaman ex Bereau (Bignoniaceae). J Med Plant Res 2008;2(8):180-8.

16. Kelly GS. The role of glucosamine sulfate and chondroitin sulfates in the treatment of degenerative joint disease. Altern Med Rev 1998;3(1):27-39.

17. Sherman AL, Ojeda-Correal G, Mena J. Use of glucosamine and chondroitin in persons with osteoarthritis. PM R 2012;4 5 Suppl: S110-6.

18. Mishra K, Dash AP, Swain BK, Dey N. Anti-malarial activities of Andrographis paniculata and Hedyotis corymbosa extracts and their combination with curcumin. Malar J 2009;8(26):26. 